\title{
Estrategias del Museo Etnográfico J. B. Ambrosetti frente a la restitución de restos humanos
}

Anne Gustavsson

\section{(2) OpenEdition}

Journals

\section{Electronic version}

URL: http://journals.openedition.org/corpusarchivos/950

DOI: 10.4000/corpusarchivos.950

ISSN: $1853-8037$

\section{Publisher}

Diego Escolar

\section{Electronic reference}

Anne Gustavsson, «Estrategias del Museo Etnográfico J. B. Ambrosetti frente a la restitución de restos humanos », Corpus [En línea], Vol 1, No 1 | 2011, Publicado el 30 junio 2011, consultado el 19 abril 2019. URL : http://journals.openedition.org/corpusarchivos/950 ; DOI : 10.4000/ corpusarchivos.950

This text was automatically generated on 19 April 2019. 


\title{
Estrategias del Museo Etnográfico J. B. Ambrosetti frente a la restitución de restos humanos
}

\author{
Anne Gustavsson
}

1 El Museo Etnográfico J. B. Ambrosetti (MEA) cuenta con una de las mayores y más antiguas colecciones de restos humanos en el país. Esto se debe a que reúne tanto las colecciones generadas por el MEA y aquellas heredadas en 1947 del Museo Argentino de Ciencias Naturales Bernardino Rivadavia (MACNBR). Las colecciones se dividen actualmente en tres categorías y están guardadas en depósitos separados: Etnografía, Antropología Física y Arqueología. En este artículo me concentraré en la colección de Antropología Física. Específicamente, analizaré las estrategias implementadas en relación con la restitución de restos humanos.

2 Las colecciones de esta sección, que consisten principalmente en restos humanos indígenas, están en la actualidad en peores condiciones que las otras colecciones en términos de documentación, conservación y acceso ya que recién en 2007 se inicia un proyecto de inventariado sistemático. Este desarrollo tardío puede ser entendido analizando de qué manera los restos humanos han sido valorizados por el MEA en el pasado.

3 Durante las pasadas dos décadas (1986-2005), bajo la dirección de José Antonio Pérez Gollán, el Museo fue sometido a muchos cambios y hoy en día es reconocido como un pionero en el campo de la museología. Uno de los principales objetivos durante la década del 1990 fue realizar un inventario completo de todas las colecciones, para posteriormente trabajar en aspectos de conservación de manera de asegurar la preservación del patrimonio. Estos dos pasos eran considerados fundamentales para alcanzar el objetivo máximo del Museo: ser accesible e interesante al público (Pérez Gollán y Dujovne 1988, 1996). Debido a que el Museo se adhirió a una política de no exhibición de restos humanos y a que el principal objetivo era trabajar con las colecciones que iban a ser exhibidas al público, las secciones de Etnografía y Arqueología fueron 
priorizadas en términos de recursos, conservación y capacitación del personal. Al ser consultado acerca de cuestiones vinculadas a la conservación en el MEA, Pérez Gollán resaltó que las colecciones de restos humanos son pequeñas y que históricamente jugaron un papel menor en la producción científica del Museo. Asimismo, admitió que ningún miembro del personal entrenado en conservación preventiva estaba interesado en hacerse cargo de la sección de Antropología Física (Pérez Gollán, comunicación personal). Como resultado, las colecciones de restos humanos continuaron sufriendo de inventarios incompletos y pobre conservación. Si bien tenían un posible valor científico, carecían de valor educativo.

4 Básicamente, los restos humanos del MEA constituyen una colección pública pero en los últimos treinta años su manejo ha sido enfocado hacia la investigación. En este sentido, los materiales no son considerados un bien público sino una responsabilidad individual de los investigadores. Se han realizado en numerosas ocasiones inventarios parciales de las colecciones para ser utilizados en proyectos de investigación. Esto resulta evidente en el título del catálogo de 1988: "Catálogo de Antropología Física 1988 Tomo 1 y 2, Proyecto de Investigación Anual, Secretaría de Ciencia y Técnica, CONICET-PID n. 256 Genética y Microevolución de poblaciones del área andina, modelo de catalogación operativa PIAUBA FI018, Director del proyecto Lic. Carlos J. Reynoso, Etapa: Catalogación e Inventario". Únicamente el material que iba a ser estudiado fue localizado y registrado. Esta resistencia a percibir las colecciones como un bien público y la predominancia de la investigación por sobre el acceso general -evitando realizar inventarios sistemáticoshan sido identificadas como obstáculos en la construcción de una base de conocimiento acerca del verdadero contenido de la sección de Antropología Física.

Por otro lado, en mayo de 2004 el MEA repatrió un toi moko - una cabeza momificada y tatuada como un guerrero maorí- al National Museum of New Zealand Te Papa Tongarewa. La iniciativa partió del Director del MEA, Pérez Gollán, cuando el embajador de Nueva Zelanda en Argentina visitó el Museo en 2003 (Pegoraro y Pérez Gollán 2004). Esta cabeza que fue ingresada al catálogo en 1910 como parte de una colección mayor de objetos muy valiosos de la Polinesia, fue uno de los pocos restos humanos que se alojaron en la sección de Etnografía y no en la de Antropología Física. El hecho de que el Museo Te Papa se dedique especialmente a temas de repatriación de este tipo de cabezas y que existe bibliografía acerca del contexto en el cual estas cabezas se volvieron un bien de cambio fueron reconocidos oficialmente como factores determinantes en la decisión de repatriación. Como mencionamos anteriormente el museo también adhirió a políticas de no exhibición de restos humanos. Consideramos que con estas acciones el MEA se convirtió en pionero en la Argentina en aspectos vinculados a la consideración de la dimensión ética en lo que atañe a restos humanos. Una imagen de corrección política estaba siendo construida.

6 Esta imagen y este discurso probablemente se construyeron como respuesta a lo que estaba sucediendo en otro museo universitario con grandes colecciones de res-tos humanos, el Museo de Ciencias Naturales de la La Plata (MCNLP). En la Argentina existen dos casos paradigmáticos en los cuales restos indígenas han sido restituidos a comunidades indígenas. Ambos conciernen al MCNLP. En abril de 1994 los restos de Inakayal fueron restituidos y depositados en un mausoleo en la pequeña ciudad patagónica de Tecka (Politis 200:98). El segundo caso se trata de la restitución en 2001 del cacique ranquel Panghitruz Guor, también conocido como Mariano Rosas, a una comunidad ranquel en la provincia de La Pampa (Endere 2007). Resulta interesante que en 
ambos casos los restos tienen una identidad conocida y que sucedieron gracias a leyes específicas. Recién en 2006, después de más de una década de reclamos y críticas de diferentes actores, el Consejo Académico de la Facultad de Ciencias Naturales de la Universidad de La Plata resolvió que el Museo no volvería a exhibir restos huma-nos de indígenas americanos, garantizaría su apropiada conservación y apoyaría la restitución de restos huma-nos indígenas identificados.

El caso del MCNLP está muy presente en el MEA y habitualmente se realizan comparaciones entre ambos museos. La Dra. Inés Baffi, una investigadora que ha analizado parte de las colecciones de restos humanos en el MEA desde 1984, afirma que estas colecciones son diferentes de las alojadas en el MCNLP ya que sólo se han identificado con nombres individuos africanos, asiáticos y europeos pero no indígenas americanos (Baffi, comunicación personal). En el mismo sentido, Pérez Gollán diferencia ambos museos afirmando que el MCNLP re-colectaba y estudiaba razas contemporáneas en mucha mayor medida. Según este investigador, la mayor parte de las colecciones del MEA provienen de excavaciones arqueológicas (Pérez Gollán, comunicación personal).

Como se evidencia en sus testimonios, ambos profesionales diferencian las colecciones de restos humanos del MEA de las del MCNLP ya que en el primero la mayor parte del material proviene de excavaciones arqueológicas, y en el segundo, el estudio de la diversidad humana pasada y presente estaba bien desarrollado y las colecciones de grupos étnicos contemporáneos eran mayores. En consecuencia, resultaba lógico concluir que el MEA no tenía restos humanos indígenas identificables a diferencia de lo que ocurría en el MCNLP. Se podría argumentar que la distinción también fue resaltada por la repatriación de la cabeza maorí, un proceso que no fue consecuencia de una historia de reclamos sino de la propia iniciativa de Museo. Todos estos elementos sirven para construir y reforzar el discurso oficial de corrección política del Museo.

9 Las colecciones de restos humanos en el MEA tienen alrededor de 10.000 elementos. Este número sólo puede ser confirmado una vez que el inventario actualizado de los restos humanos sea completado. Es importante subrayar que esta colección constituye aproximadamente un sexto del tamaño total de las colecciones del MEA. En comparación con la actualidad, durante los años más importantes en la conformación de las colecciones del MEA, los restos humanos constituían una pequeña proporción (alrededor del 4-6\%). Si observamos la in-formación acerca de las primeras colecciones de restos humanos en el MEA ${ }^{1}$ podemos ver que estos constituían aproximadamente el $6.2 \%$ del total de los objetos entra-dos entre 1904 y 1910; 380 de los 394 ingresos de restos humanos provienen de expediciones de la Facultad de Filosofía y Letras (FFyL) de la Universidad de Buenos Aires. Precisamente es durante este periodo que estas expediciones trajeron la mayor parte del material osteológico. En 1916 el escenario es muy similar con un total de 21.572 ítems ingresados en los catálogos generales de los cuales 975 son cráneos y otras partes esqueletares, lo que corresponde a un $4.5 \%$ del total aproximadamente (Informe anual 1916 e Inventario de 1916) ${ }^{2}$. Si comparamos esto con el porcentaje actual (17\% del total es material del depósito de Antropología Física que no sólo incluye restos humanos) vemos que cerca del $90 \%$ de las colecciones de Antropología Física entraron al Museo después de 1916. Esto significa que casi todos los restos humanos entraron al museo por causas no relacionadas a las primeras expediciones arqueológicas. También significa que estas colecciones ingresaron al Museo después del periodo en que las colecciones del MEA crecieron de forma más rápida. 
10 En contraste con los primeros años del Museo en los cuales casi todos los restos humanos provinieron de las excavaciones arqueológicas realizadas por la FFyL, durante la década de 1910 un número creciente de elementos procedieron de contextos que no eran necesaria-mente arqueológicos. En la Memoria del Museo Etnográfico, 1906-1912, y en los informes anuales inéditos de entre 1906 y 1917 encontramos referencia a grupos étnicos contemporáneos como los onas, yamanas, mocovís, chiriguanos, pilagás y tobas. Por ejemplo, en el informe anual presentado por Ambrosetti que cubría las actividades del Museo durante 1913 y 1914, no hay menciones de grupos étnicos pero sí de los restos de cierto cacique indígena llamado Illirí y de su hijo. En los informes anuales de 1916 y 1917 observamos el ingreso de muchos res-tos pertenecientes a grupos étnicos contemporáneos. Es interesante agregar que el informe anual de 1916 revela que muchos objetos de matacos, chiriguanos y pilagas ingresaron a la sección de Etnografía del MEA. ¿Habrán sido los restos humanos recogidos en el mismo momento que los objetos etnográficos? ¿Habrán sido excavados cementerios contemporáneos o sitios rituales?

11 Los restos humanos han sido clasificados, en el caso del MEA, como etnográficos o antropológicos. Además, muchos de ellos fueron recogidos en excavaciones arqueológicas, aunque no están explícitamente considera-dos como material arqueológico en los informes anua-les y en la Memoria del Museo Etnográfico, 1906-1912. Una vez ingresados al museo, todos los restos humanos, sin importar si provenían de contextos arqueológicos u otros, eran reunidos en la sección de Antropología Física. De acuerdo a la descripción realizada anteriormente de las primeras colecciones, la antigüedad del material y la forma en que fue recuperado parecen variar.

12 A modo de resumen, este estudio sugiere que ha existido una resistencia a percibir las colecciones de restos humanos del MEA como un bien público y patrimonial y que este tipo de colecciones han tenido históricamente escaso valor para la institución. Debido a la baja priori-dad dada a las políticas de conservación y documentación de restos humanos había, al menos hasta el 2008, sólo un conocimiento parcial acerca del contenido de las colecciones de restos humanos. De cualquier manera, se asume y afirma que la mayor parte de ellos proviene de excavaciones arqueológicas y que no hay restos humanos identificables de indígenas de la Argentina en el MEA aunque los catálogos, memorias e informes anuales del Museo indican otra historia de conformación de colecciones. Además, existe un discurso de corrección política que se observa en la implementación de una política de no exhibición de restos humanos, en una identidad institucional diferenciada del MCNLP y en la repatriación de una cabeza maorí a Nueva Zelanda. Es posible que estos elementos de corrección política junto con el des-conocimiento de qué y quiénes están contenidos en las colecciones constituya una estrategia para evadir la discusión de problemáticas sensibles en el MEA y de esta manera evitar reclamos de restitución por parte de las comunidades indígenas.

BIBLIOGRAPHY 


\section{Fuentes del Archivo Fotográfico y Documental del Museo Etnográfico Juan Bautista Ambrosetti}

Ambrosetti, J. B. Memoria (1913-1914) del Director del Museo Etnográfico, 1914.

Ambrosetti, J. B. Informe anual del Museo Etnográfico, 19 de abril 1915.

Ambrosetti, J. B. Informe anual del Museo Etnográfico, 26 de abril 1916.

Ambrosetti, J. B. Informe anual del Museo Etnográfico, 20 de abril 1917.

Inventario de Museo Etnográfico, Colecciones, 7 de Noviembre 1916.

Ambrosetti, Juan B. (1912). Memoria del Museo Etnográfico, 1906-1912. Buenos Aires: Compañía SudAmericana de Billetes de Banco.

Endere, M. L. (2007). Management of Archaeological Sites and the Public in Argentina, BAR

International Series. Archaeopress: Oxford.

Pérez Gollán, J. A. y Dujovne M. (1988). El museo etnográfico: funciones, diagnóstico y propuestas.

Buenos Aires, mimeo.

Pérez Gollán, J.A. y Dujovne M. (1996). El museo etnográfico: funciones y balance de una gestión. Runa, Archivo para las Ciencias del Hombre XXII, 119-131.

Pérez Gollán, J. A. y Pegoraro A. (2004). La repatriación de un Toi Moko. Relaciones de la Sociedad Argentina de Antropología XXIX.

Politis, G. (1994). El Regreso de Inakayal. Museo 1 (3).

\section{NOTES}

1. El material consultado constituye el primer catálogo general que cubre todos los ingresos al Museo entre 1904 y 1910, la Memoria del Museo Etnográfico, 1906-1912, publicada por Ambrosetti en 1914 y los informes anuales del MEA entre 1915-1917, así como un inventario de antropología de 1916.

2. El inventario menciona solo cráneos y esqueletos, mientras que los huesos sueltos en algunos casos son ingresados con números separados en el catálogo general. Esto podría hacer que los números sean algo inexactos pero sirven para darnos una idea del bajo porcentaje de las colecciones que constituía la sección de Antropología.

\section{AUTHOR}

\section{ANNE GUSTAVSSON}

Centro de Estudios de Historia de la Ciencia y de la Técnica José Babini, Escuela de Humanidades, Universidad Nacional de General San Martín.

Correo electrónico: anne.gustavsson@gmail.com 